\title{
Effects of addition of strawberry juice pre- or postfermentation on physiochemical and sensory properties of fermented goat milk
}

\author{
H. Wang, ${ }^{1}$ C. N. Wang, ${ }^{2}$ and M. R. Guo ${ }^{1,3 *}$ \\ ${ }^{1}$ College of Food Science and Engineering, Northeast Agricultural University, Harbin, Heilongjiang, 150001, China \\ ${ }^{2}$ Department of Food Science, College of Food Science and Engineering, Jilin University, Changchun, Jilin, 130062, China \\ ${ }^{3}$ Department of Nutrition and Food Sciences, College of Agriculture and Life Sciences, University of Vermont, Burlington 05405
}

\section{ABSTRACT}

Fruit juice addition can influence the physiochemical and sensory properties of fermented milk. Effects of adding strawberry juice $(15 \% \mathrm{vol} / \mathrm{vol})$ pre- or postfermentation on particle size, rheology properties, volatile flavor profile, and microstructure of fermented goat milk were investigated. Samples with juice added prefermentation showed larger reinforcement in particle size, apparent viscosity, and storage and loss moduli than samples with juice added postfermentation. Compared with the control, all samples showed improved fruit aroma and reduced goaty flavor; this effect was more remarkable in samples in which juice was added before fermentation. Fermented goat milk with strawberry juice added prefermentation showed the highest levels of 1-hexanol and 2-hexen-1-ol (26.16 and 22.03\%, respectively) and the lowest percentage of octanoic acid $(2.47 \%)$, which are mainly responsible for fruit and goaty flavor, respectively. Microstructure analysis showed that samples with juice added prefermentation had a compact protein network. Results indicated that addition of strawberry juice before fermentation may be a good technology for developing a stirred strawberry fermented goat milk.

Key words: fermented goat milk, strawberry juice, physical property, volatile profile

\section{INTRODUCTION}

Goat milk is the second most consumed milk in the world (Varga et al., 2014). It may be more digestible due to its high level of short-chain fatty acids and small fat globules (Schorsch et al., 2001). However, goat milk and its products often have a unique "goaty" flavor,

Received September 25, 2018.

Accepted February 12, 2019.

*Corresponding author: mguo@uvm.edu which may be mainly attributed to the high content of free octanoic acid (Young et al., 2012). The special goaty flavor may not be accepted by certain consumers, thus influencing the consumption of goat milk products (Haenlein, 2004).

Traditional kefir is a soured and mildly alcoholic fermented milk originating from the Caucasus Mountains (Wang et al., 2015b). Fermented milk made by kefir mild starter culture has a similar taste compared with kefir, but no yeast or alcoholic compound exists (Lucke and Zangerl, 2014; Wang et al., 2017). The flavor substances of fermented milk, such as nonvolatile acids, volatile acids, and carbonyl compounds, could be produced by the lactic acid bacteria from kefir mild starter culture (Ye et al., 2012). The specific strains in kefir mild starter culture could produce exopolysaccharides, which play an important role in the formation of fermented milk gel (do Espirito Santo et al., 2012).

Extensive studies have been reported on improving the flavor properties of fermented milk by adding various food ingredients. Li et al. (2014) found that Cheddar cheese addition significantly increased the aroma compounds in fermented milk. Ye et al. (2012) studied the effect of hawk tea on yogurt and found that hawk tea could significantly increase the content of acetaldehyde, diacetyl, and acetoin. Mesurolle et al. (2013) reported that fruit addition plays an important role in the aroma release of fermented milk. Sugar and pectin in the fruit juice could increase the volatility of flavor compounds by physiochemical interactions (Nongonierma et al., 2006). Fruit addition could mask the excessive intolerant flavor in fermented milk and thus improve the sensory properties (Senaka Ranadheera et al., 2012; Temiz et al., 2018).

Fruit-flavored products increased the annual consumption of fermented milk in many countries (Temiz et al., 2018; Turgut and Cakmakci, 2018). As the most popular berry fruit worldwide (FAO, 2016), strawberry has been used for fermented milk production for many years. It is usually added during fermentation of stirred fermented milk products. Different addition technology 
may change the structural properties of the samples and particle size, rheological properties, and microstructure (Espírito-Santo et al., 2013). In this study, we investigated the effects of addition of strawberry on the particle size distributions, rheology properties, flavor compounds, and microstructures of fermented goat milk.

\section{MATERIALS AND METHODS}

\section{Materials}

Goat milk powder and $8 \times$ concentrated strawberry juice were provided by Huacheng Biological Corporation (Changchun, Jilin, China). Freeze-dried kefir mild 01 starter culture (Lactococcus lactis ssp. lactis, Lc. lactis ssp. cremoris, Lc. lactis ssp. lactis biovar diacetylactis, Leuconostoc mesenteroides ssp. mesenteroides, Streptococcus thermophilus, and Lactobacillus acidophilus) was purchased from Danisco (Beijing, China). Low-methoxyl pectin (LM-106AS) was obtained from Cpkelco (Lille Skensved, Denmark). Whey protein isolate $(93.14 \%$ wt/ wt protein) was purchased from Fonterra Co-operative Group (Auckland, New Zealand). Deionized water was obtained using a deionization reversed osmosis system (Millipore Corp., Burlington, MA).

\section{Preparation of Stirred Strawberry Fermented Goat Milk}

Polymerized whey protein (PWP) was prepared using $10 \%$ (wt/vol) whey protein isolate solution according to the method of Wang et al. (2015a). The process for preparing stirred strawberry fermented goat milk is shown in Figure 1. Goat milk powder was dissolved in deionized water to reconstitute goat milk (12.5\% wt/vol). Pectin (0.2\% wt/vol) and PWP $(0.3 \%$ wt/vol) were added to the goat milk and subjected to heat treatment $\left(85^{\circ} \mathrm{C} / 10 \mathrm{~min}\right.$; Wang et al., 2017). After heat treatment, the mixtures were cooled to $28^{\circ} \mathrm{C}$ in an ice bath.

\section{Preparation of Samples with Strawberry Juice Added Prefermentation}

Concentrated strawberry juice $(1.875 \mathrm{~mL})$ was added to the abovementioned mixture $(100 \mathrm{~mL})$ to make the final juice concentration $15 \%$ ( $\mathrm{vol} / \mathrm{vol})$ and then stirred at $150 \mathrm{rpm}$ for $3 \mathrm{~min}$ by a magnetic stirrer (IKA Ared, Pedrollo, Italy). All mixtures were inoculated with kefir mild 01 starter culture $(0.01 \% \mathrm{wt} / \mathrm{vol})$ and then fermented at $28^{\circ} \mathrm{C}$ until $\mathrm{pH}$ reached $4.5 \pm 0.1$. Samples were stirred at $150 \mathrm{rpm}$ for $3 \mathrm{~min}$ and then distributed in 50-mL sterile plastic containers and stored at $4^{\circ} \mathrm{C}$.

\section{Preparation of Samples with Strawberry Juice Added Postfermentation}

The mixtures were inoculated with kefir mild starter culture and then fermented at $28^{\circ} \mathrm{C}$ until pH reached $4.5 \pm 0.1$. Concentrated strawberry juice $(1.875 \mathrm{~mL})$ was added to the fermented milk $(100 \mathrm{~mL})$ and stirred at $150 \mathrm{rpm}$ for $3 \mathrm{~min}$. Samples were distributed in 50$\mathrm{mL}$ sterile plastic containers and then stored at $4^{\circ} \mathrm{C}$. Samples without fruit juice were used as controls. Each experiment was carried out for 3 trials, and each trial was conducted in triplicate.

\section{Particle Size Measurement}

Particle size of all samples was determined using a Mastersizer 3000 Analyzer (Malvern Instruments, Worcestershire, UK). Samples were stirred at $150 \mathrm{rpm}$ for 10 min before test and then transferred to a measuring cell containing distilled water with obscuration of $20 \pm 1 \%$. The refractive index of sample and water was 1.46 and 1.33, respectively. Three repetitions were made for each sample, separated by $10 \mathrm{~s}$, and were averaged. Particle size distribution and particle span were used to characterize the particle size; D50 indicates the volume median diameter, and D90 and D3,2 display the mean diameter of coarser and finer particles in the sample, respectively. Particle span represents the width of the particle distribution and is calculated using the following equation:

$$
\text { particle span }=(\mathrm{D} 90-\mathrm{D} 10) / \mathrm{D} 50,
$$

where D10 represents the particle diameter corresponding to $10 \%$ cumulative (from 0 to $100 \%$ ) undersize particle size distribution.

\section{Rheological Characterization}

Rotational and dynamic oscillatory rheology of all samples was carried out using a rheometer (DHR-1, TA Instruments, New Castle, DE) equipped with a cone-plate geometry (diameter $=40 \mathrm{~mm}$; angle $=2^{\circ}$; gap $=52 \mu \mathrm{m}$ ) according to the method of Buldo et al. (2016) with some modifications. The measuring system was tempered at $10^{\circ} \mathrm{C}$ using an integrated Peltier unit. Samples were stirred at $150 \mathrm{rpm}$ for $3 \mathrm{~min}$ before loading. Strain sweep test $\left(1 \mathrm{rad} / \mathrm{s}, 1 \times 10^{-3}\right.$ to $1 \times$ $10 \%$ strain) was used to analyze the linear viscoelastic region first. Rotational and dynamic oscillatory rheology were conducted by using flow test $\left(1 \times 10^{-3}\right.$ to 300 $\mathrm{s}^{-1}$, then hold at $300 \mathrm{~s}^{-1}, 300$ to $1 \times 10^{-3} \mathrm{~s}^{-1}$, within 10 min for each ramp) and frequency sweep measurement (0.5\% strain, $0.1-100 \mathrm{~Hz}$ ), respectively. 


\section{Headspace Solid-Phase Microextraction} of Flavor Compounds

Fermented goat milk volatile was extracted according to the method described by Pan et al. (2014) and Ye et al. (2012) with some modifications. Sample (5.0 g) and $\mathrm{NaCl}(3.0 \mathrm{~g})$ were put into glass bottles $(20 \mathrm{~mL}$; Supelco, Bellefonte, PA) with a polytetrafluoroethylene septum and heated in a water bath at $60^{\circ} \mathrm{C}$ for $10 \mathrm{~min}$ to equilibrate. Then, a solid-phase microextraction sy- ringe with Car/PDMS fiber needle (75 $\mu \mathrm{m}$; Supelco) was used to penetrate the septum for extraction at $60^{\circ} \mathrm{C}$ for $45 \mathrm{~min}$.

\section{GC-MS Analysis of Flavor Compounds}

Volatiles of all samples were analyzed by a Shimadzu GC-MS 2010 (Kyoto, Japan). A solid-phase microextraction fiber needle after extraction was immediately inserted into the injection port, then held at $250^{\circ} \mathrm{C}$

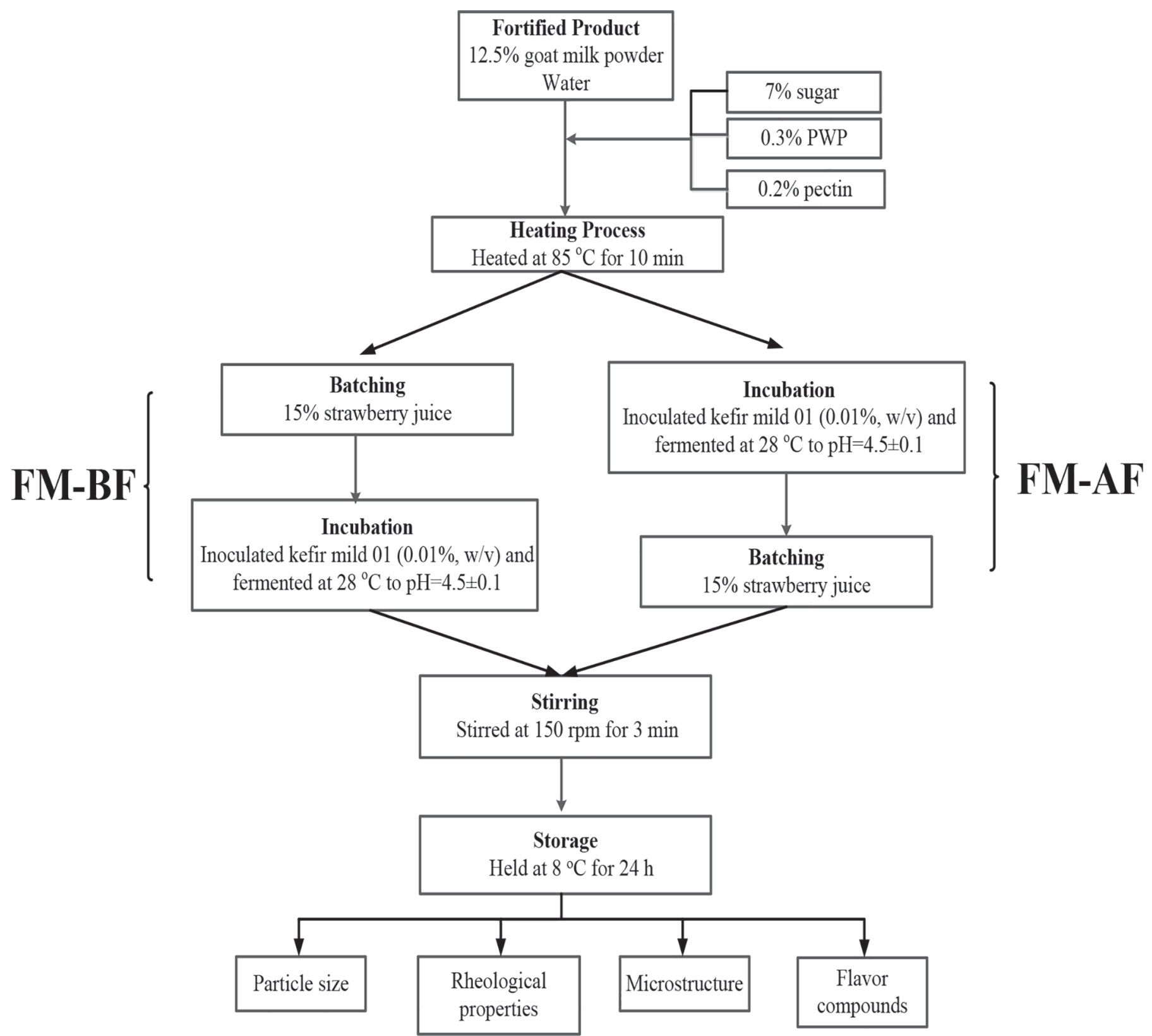

Figure 1. Flowchart of developing strawberry stirred fermented goat milk and control. FM-BF = samples with strawberry juice added prefermentation; FM-AF = samples with strawberry juice added postfermentation; PWP $=$ polymerized whey protein. 
for 5 min with an injection mode of splitless. An HPInnowax column $(60 \mathrm{~m} \times 0.25 \mathrm{~mm} \times 0.25 \mu \mathrm{m}$; Agilent Technologies, Santa Clara, CA) was used to separate the flavor compounds.

The temperature program was as follows: held at $45^{\circ} \mathrm{C}$ for $10 \mathrm{~min}$, increased from 45 to $240^{\circ} \mathrm{C}$ at a rate of $5^{\circ} \mathrm{C} / \mathrm{min}$, and then held at $240^{\circ} \mathrm{C}$ for $5 \mathrm{~min}$. The carrier gas was helium $(1 \mathrm{~mL} / \mathrm{min})$. The mass spectrometer was run in electron ionization mode $(70 \mathrm{eV})$ with an iron source temperature at $200^{\circ} \mathrm{C}$. The mass scan range was 25 to 400 mass:charge ratio (Li et al., 2014). Volatiles were determined by comparing the retention time of samples with that in the NIST08 mass spectrum database location. Results are presented as retention time and relative peak area.

\section{Microstructure Analysis by Confocal Laser Scanning Microscopy}

Microstructures of the fermented goat milk samples were analyzed according to the method of Mokoonlall et al. (2016c) and Krzeminski et al. (2011) using an FV3000 confocal laser scanning microscope (Olympus Corp., Tokyo, Japan) with a $63 \times$ oil immersion objective. The excitation wavelengths of 543 and $654 \mathrm{~nm}$ were provided by krypton-argon laser. Rhodamine B (Sigma-Aldrich, St. Louis, MO) was solubilized in distilled water at a level of $0.012 \mathrm{~g} / 100 \mathrm{~g}$, and V03-01136 Fat Red (Dyomics, Jena, Germany) was dissolved in polyethylene glycol 200 (Sigma-Aldrich) at $0.02 \mathrm{~g} / 100$ g. Rhodamine B and V03-01136 were used to stain for protein and fat, respectively. Protein and fat were red and green in the confocal laser scanning microscopy software.

\section{Statistical Analysis}

The data were analyzed using SPSS version 21.0 (SPSS Inc., Chicago, IL) with the significance level at $P<0.05$. The figures were drawn by Origin 2018 (OriginLab Corp., Northampton, MA).

\section{RESULTS AND DISCUSSION}

All fermented goat milk was inoculated with kefir mild 01 starter culture $(0.01 \% \mathrm{wt} / \mathrm{vol})$ and then fermented at $28^{\circ} \mathrm{C}$ until pH reached $4.5 \pm 0.1$. These optimal fermentation conditions were set according to the manual of starter culture provided by the manufacturers and our previous study (Wang et al., 2017). All the samples with strawberry juice addition pre- or postfermentation were analyzed for particle size distribution, rheology properties, flavor compounds, and microstructures.

\section{Effects of Adding Strawberry Juice Pre- or Postfermentation on Particle Size of Stirred Fermented Goat Milk}

Particle Size Distribution. Particle size distribution of all samples was shown in Figure 2. Three independent peaks (peak 1: 0 1.0 $\mu \mathrm{m}$; peak 2: 1.0 50 $\mu \mathrm{m}$; peak 3: $>50 \mu \mathrm{m})$ were observed. Peak 1 may be for the free particles that did not participate in milk gelation. Peak 3 seemed to be the peak of the aggregated particles, whereas peak 2 presented the majority of particles in the samples. Compared with the control and samples with strawberry juice added postfermentation (FM-AF), the particle distribution of samples with strawberry juice added prefermentation (FM-BF; Figure 2) showed a right shift and wide tendency, suggesting an increased particle size and extended particle span.

D50, D90, D3,2, and Particle Span. The D50, D90, D3,2, and particle span of all samples were evaluated based on the particle size distribution, and the results are shown in Table 1 . The particle size range of all samples corresponded to the protein microgels obtained after stirring the fermented milk gel (Huc et al., 2016).

Compared with the control, the D50 of FM-BF was significantly increased $(P<0.05)$, whereas that of FM-AF showed no significant changes $(P>0.05)$, and the D50 of FM-BF was significantly higher than that of FM-AF $(P<0.05)$. This phenomenon may be due to the difference in fermentation substrate conditions

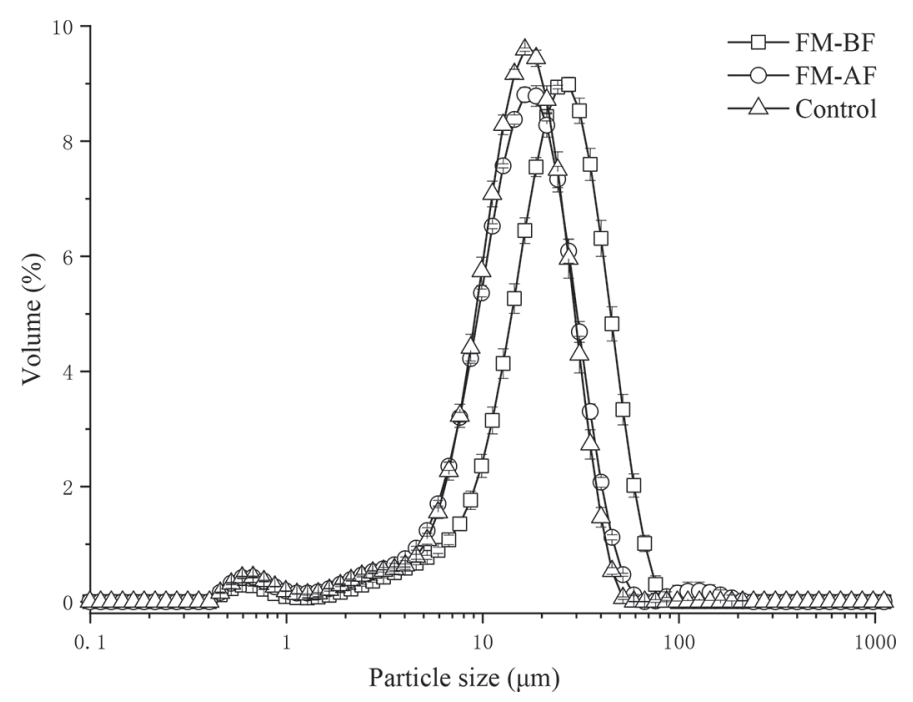

Figure 2. Particle size distributions of samples with strawberry juice added prefermentation (FM-BF), samples with strawberry juice added postfermentation (FM-AF), and control. Values are reported as mean $\pm \mathrm{SD}$. 
Table 1. Effects of strawberry juice addition pre- or postfermentation on particle size ${ }^{1}$ of stirred fermented goat milk

\begin{tabular}{lcccc}
\hline Sample $^{2}$ & D50 $(\mu \mathrm{m})$ & D90 $(\mu \mathrm{m})$ & D3,2 $(\mu \mathrm{m})$ & Particle span \\
\hline FM-BF & $24.77 \pm 0.72^{\mathrm{a}}$ & $47.47 \pm 1.17^{\mathrm{a}}$ & $13.03 \pm 0.32^{\mathrm{a}}$ & $1.60 \pm 0.02^{\mathrm{a}}$ \\
FM-AF & $16.90 \pm 0.10^{\mathrm{b}}$ & $33.50 \pm 0.46^{\mathrm{b}}$ & $9.20 \pm 0.08^{\mathrm{b}}$ & $1.60 \pm 0.05^{\mathrm{a}}$ \\
Control & $16.50 \pm 0.44^{\mathrm{b}}$ & $30.50 \pm 0.52^{\mathrm{c}}$ & $9.20 \pm 0.28^{\mathrm{b}}$ & $1.43 \pm 0.02^{\mathrm{b}}$ \\
\hline
\end{tabular}

${ }^{a-c}$ Means within a column with different superscripts are significantly different $(P<0.05)$.

${ }^{1}$ D50 indicates the volume median diameter, and D90 and D3,2 display the mean diameter of coarser and finer particles in the sample, respectively.

${ }^{2} \mathrm{FM}-\mathrm{BF}=$ samples with strawberry juice added prefermentation; FM-AF $=$ samples with strawberry juice added postfermentation.

(e.g., the level of polysaccharide, sugar, or $\mathrm{pH}$ ) when fruit juice was added pre- or postfermentation (Mesurolle et al., 2013).

Rough and grainy textures have been perceived by taste panelists when the particle size of fermented dairy products was greater than $150 \mu \mathrm{m}$, and D90 can be used as an important parameter to describe the large particles in fermented goat milk (Cayot et al., 2008; Krzeminski et al., 2011). The D90 of all samples was smaller than $47.47 \pm 1.17 \mu \mathrm{m}$. The D90 in FM-BF was higher than that of FM-AF and the control, and the difference was significant $(P<0.05)$.

The D3,2 for both FM-BF and FM-AF showed results consistent with those of D50 compared with the control. There was significant difference in D3,2 between FM-BF and FM-AF $(P<0.05)$, indicating that fruit juice addition technology could apparently influence smaller particles of fermented milk. The highest value was $13.03 \pm 0.32 \mu \mathrm{m}$ in the sample with the addition of strawberry juice prefermentation.

The values of particle span in both FM-BF (1.60 $\pm 0.02)$ and FM-AF $(1.60 \pm 0.05)$ were significantly higher than that of the control $(P<0.05)$, suggesting that strawberry juice may disrupt the consistency of samples. The result was consistent with that of particle size distribution (Figure 2).

\section{Effect of Strawberry Juice Addition Pre- or Postfermentation on Rotational Rheology of Stirred Fermented Goat Milk}

Flow Curve. Flow test is an important analytical method for evaluating the structure of fermented milk. Figure 3a illustrates shear thinning behavior of stirred fermented goat milk samples at shear rate from $1 \times$ $10^{-3}$ to $300 \mathrm{~s}^{-1}$. The maximum volume packing density may increase when shear stress is applied, resulting in decreased apparent viscosity of the sample (Mokoonlall et al., 2016a). Pseudoplastic fluid characters were found for both FM-BF and FM-AF. Similar results were re- ported by Dimitreli et al. (2013). For FM-BF, flow curve displayed a high flow behavior with increased apparent viscosity. However, addition of juice postfermentation resulted in an obvious overlap with the control, indicating that the effect of strawberry juice addition postfermentation on rotational rheology was slight. Fruit juice addition could cause a change in the internal structure of samples during fermentation (Nguyen et al., 2017). Similar results have been reported by Bueno et al. (2014). Pectin or plant polysaccharide in juice with a negative charge could interact with positive charges in casein micelle PWP and then form a highly structured network, which may contribute to the increased apparent viscosity.

Flow curves of a non-Newtonian pseudoplastic fluid can be described by the Sisko model (Dimitreli et al., 2013). Good fits were obtained with a high correlation coefficient $\left(\mathrm{R}^{2}>0.9996\right)$ :

$$
\eta=\eta_{\infty 0}+k_{0} \dot{\gamma}^{n_{0-1}}
$$

where $\eta$ is the apparent viscosity, $\eta_{\infty 0}$ is the high shear rate-limiting viscosity, $k_{0}$ is the consistency index, $\gamma$ is the shear rate, and $n_{0}$ is the flow index, being $<1$ for pseudoplastic fluids.

The parameters derived from the fitting curves were shown in Table 2. The $k_{0}$ of FM-BF was higher than that of FM-AF $(P<0.05)$ and the control $(P>0.05)$. Decourcelle et al. (2004) and Ramaswamy and Basak (1992) reported that the consistency index could be improved when berry juice was added in fermented milk prefermentation.

All values of $n_{0}$ were below 1.0, indicating a pseudoplastic behavior of stirred fermented goat milk (Espírito-Santo et al., 2013). The value of $n_{0}$ between FM-BF and FM-AF has no significant difference $(P>0.05)$ and was significantly higher than that of the control $(P<0.05)$. Brewer et al. (2016) similarly reported that addition of fruit juice could cause the fermented milk gel to depart from pseudoplastic fluid behavior. 

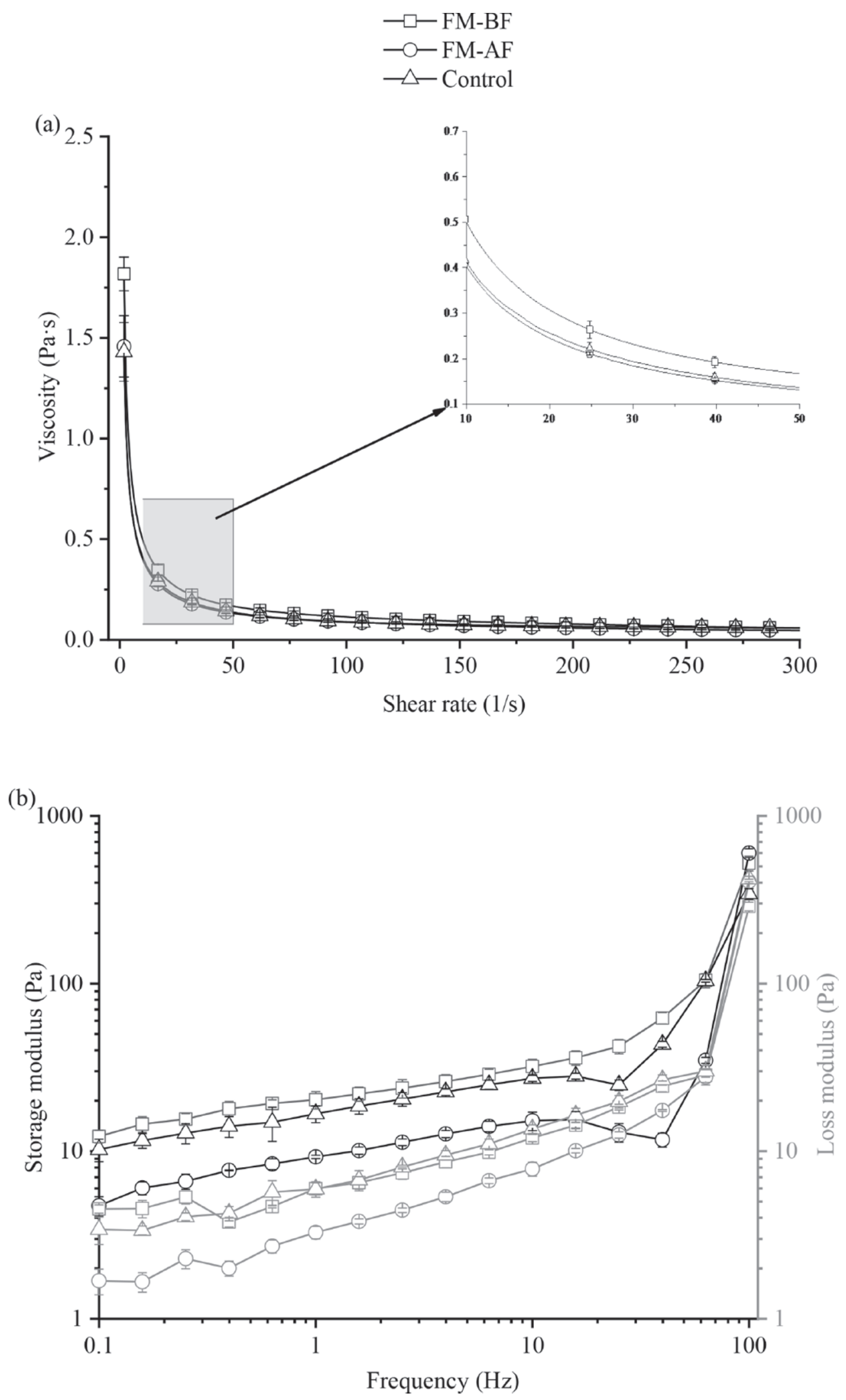

Figure 3. (a) Flow curves and (b) storage and loss moduli of samples with strawberry juice added prefermentation (FM-BF), samples with strawberry juice added postfermentation (FM-AF), and control. Values are reported as mean \pm SD. 
Viscosity at $50 \mathrm{~s}^{-1}$ and Hysteresis Loop Area. Although it was reported that oral perception of solution viscosity correlated well with viscosity measurements ranging from 10 to approximately $50 \mathrm{~s}^{-1}$ (Glibowski and Kowalska, 2012), the apparent viscosity at a shear rate of $50 \mathrm{~s}^{-1}$ was still considered to be a measure of oral texture during consumption (Mokoonlall et al., 2016b). All samples were determined for viscosity at 50 $\mathrm{s}^{-1}$ and hysteresis loop area, and the results are shown in Table 2.

The FM-BF showed significantly higher apparent viscosity at $50 \mathrm{~s}^{-1}(0.1980 \pm 0.0354 \mathrm{~Pa} \cdot \mathrm{s})$ than $\mathrm{FM}-$ $\mathrm{AF}$ and the control $(P<0.05)$. Structure (thixotropy) of samples during fermentation may be enhanced by interactions of pectin in juice and exopolysaccharides released by starter culture (Espírito-Santo et al., 2013). Mesurolle et al. (2013) also reported that addition of fruit juice in fermented milk could help modify oral behavior with increasing apparent viscosity.

Hysteresis loop area is a measure of the structure losses following the application and subsequent removal of shear. A smaller hysteresis loop area implies better recovery of the gel structure (Mokoonlall et al., 2016b). Strawberry juice addition could improve the hysteresis loop area of all samples, and the improvement was significant $(P<0.05)$. Hysteresis loop area of FM-BF $\left(19,179.62 \pm 4,862.02 \mathrm{~Pa} \cdot \mathrm{s}^{-1}\right)$ was significantly higher than that of FM-AF $(P<0.05)$, indicating a better recovery ability of FM-AF.

\section{Effect of Strawberry Juice Addition Pre- or Postfermentation on Dynamic Oscillatory Rheology of Stirred Fermented Goat Milk}

Storage and Loss Moduli. The storage and loss moduli of all stirred strawberry fermented goat milk were shown in Figure 3b. Storage modulus is related to elastic properties, and loss modulus is related to viscous properties of samples (Glibowski and Kowalska, 2012). Both storage moduli and loss moduli showed a similar change pattern. Samples exhibited higher storage modulus values than loss modulus values, suggesting more elastic or solid-like behavior in the fermented goat milk (Glibowski and Kowalska, 2012; Gentes et al., 2016). Guggisberg et al. (2011) reported that this behavior is typical for fermented dairy beverages. Generally, the curve of FM-BF was higher than that of FM-AF, indicating that strawberry juice added prefermentation could improve the intensity of the milk curd by influencing the fermentation process. Values of storage modulus increased considerably for all samples after exceeding $40 \mathrm{~Hz}$, which may be due to weak bounds stabilizing the structure of the stirred fermented goat milk. 
Storage and Loss Moduli at $1 \mathrm{~Hz}$ and Phase Angle. Storage modulus and loss modulus at $1 \mathrm{~Hz}$ and phase angle of all samples are shown in Table 2 . Mesurolle et al. (2013) reported that fermented milk is a semisolid dairy product that requires very little oral movement before swallowing. Storage and loss moduli at $1 \mathrm{~Hz}$ can be considered to be the strength of transporting the sample from the front of the mouth to the oropharynx by tongue. The storage and loss moduli of FM-BF (20.61 $\pm 8.41 \mathrm{~Pa}$ for storage modulus and 5.98 \pm 2.50 for loss modulus) were significantly higher than those of FM-AF $(9.25 \pm 0.21 \mathrm{~Pa}$ for storage modulus and $3.28 \pm 0.28 \mathrm{~Pa}$ for loss modulus; $P<0.05$ ). The results were consistent with results of viscosity at $50 \mathrm{~s}^{-1}$ and consistency index in rotation rheology.

\section{Effect of Strawberry Juice Addition \\ Pre- or Postfermentation on Flavor Profile of Stirred Fermented Goat Milk}

Gas Chromatogram of Volatiles. Aroma and flavor characteristics in fermented dairy products contributed to the complex mix of compounds (Cheng, 2010; Pan et al., 2014; Wang et al., 2015b). The total gas chromatogram of stirred strawberry fermented goat milk is shown in Figure 4, and the largest number of flavor components was obtained after 20 min. A linear positive correlation between peak area and content of volatiles has been established. Abundant volatiles were found in samples with added strawberry juice. The peak areas of both FM-BF and FM-AF were significantly higher than those of the control. Similar results have been found by Nongonierma et al. (2006), who reported that the addition of fruit juice could increase the content of flavor compounds detected by chromatography.

Volatile Compounds. The relative peak area of volatile compounds detected from FM-BF, FM-AF, and the control is given in Table 3. A total of 37 volatile compounds were identified, including ketone, acid, alcohol, and a small number of lactones. Beshkova et al. (2003) reported that the aroma and flavor of fermented milk are basically due to the production of nonvolatile acids, volatile acids, and carbonyl compounds. Various species of alcohols may be due to the different strains in kefir mild 01, which could produce complicated intracellular enzymes (Li et al., 2010; Wah et al., 2013; Wang et al., 2015b). Duan et al. (2017) reported that 1-hexanol and 2-hexen-1-ol were the main volatiles in ripe strawberry fruit. The ratio of 1-hexanol and 2-hexen-1-ol in FM-BF (26.16 and 22.03\%, respectively) and FM-AF ( 22.35 and $17.63 \%$, respectively) was higher than that in the control. In total, the content of fruit aroma compounds (e.g., 2-heptanone, 1-hexanol, or 2-hexen-1-ol) in FM-BF was higher than that in FM-AF, indicating that the fermentation process may promote the release of fruit volatiles.

Nine different fatty acids also have been identified. Butanoic acid $(5.32 \%)$ and hexanoic acid $(14.27 \%)$ in the control were higher than that in FM-BF and FMAF. Butanoic acid and hexanoic acid were formed by lactose fermentation and free fatty acid lipolysis, which could be decreased by adding fruit juice (Ye et al., 2012). Researchers (Wang et al., 2017) have reported that a pungent smell contributed to acetic acid in fermented goat milk with kefir mild 01 starter culture. Acetic acid in samples was lower than in the control $(21.39 \%)$. The volatile octanoic acid was considered to
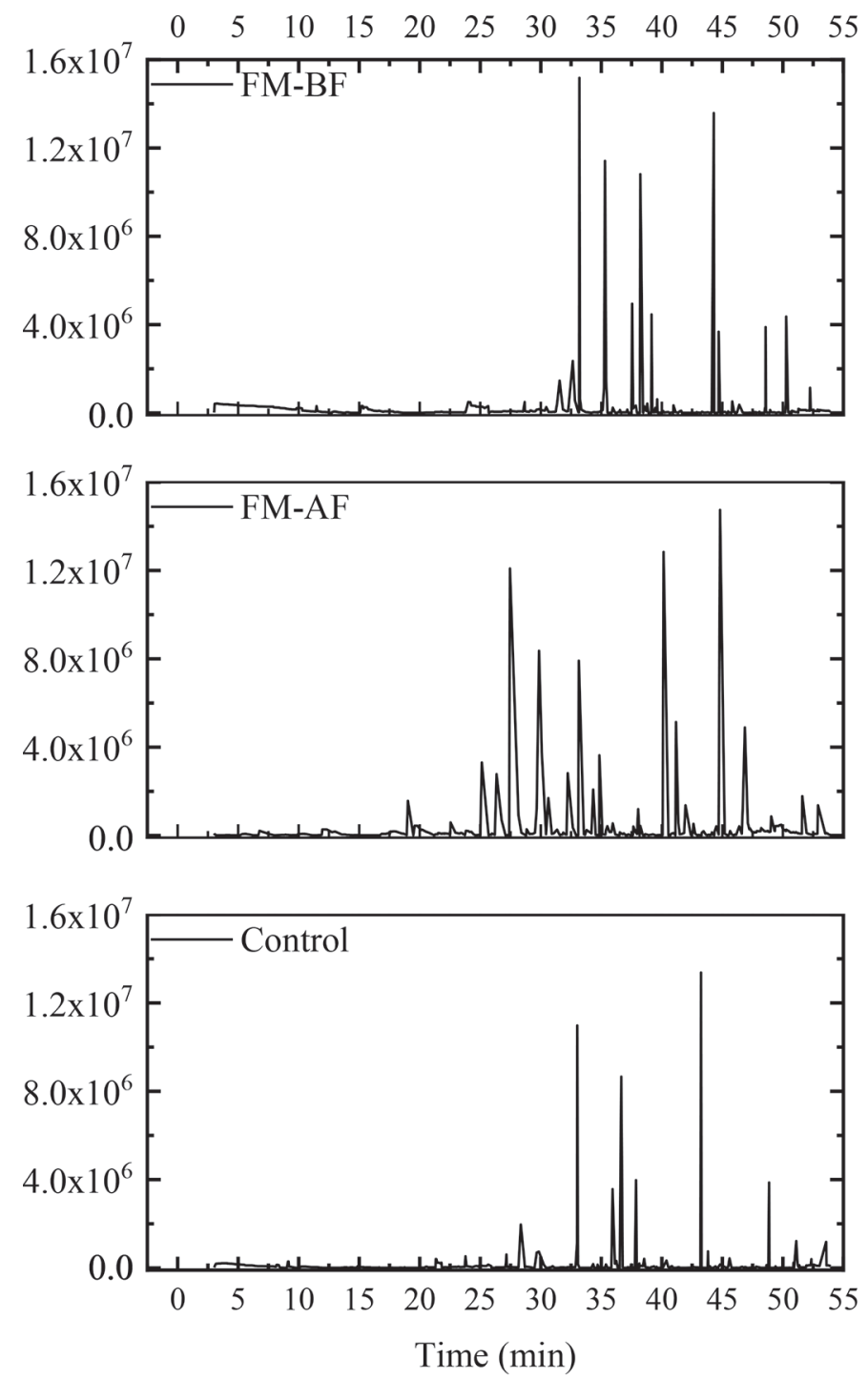

Figure 4. Gas chromatograms of volatiles in samples with strawberry juice added prefermentation (FM-BF), samples with strawberry juice added postfermentation (FM-AF), and control. 
Table 3. Relative peak area as determined by GC-MS for flavor compounds in fermented goat milk samples

\begin{tabular}{lcrrr}
\hline & & \multicolumn{3}{c}{ Relative peak area $(\%)$} \\
\cline { 3 - 5 } Compound & & & & \\
& Retention & & & \\
& time (min) & FM-BF & FM-AF & Control \\
\hline 2-Heptanone & 19.54 & 0.73 & 0.57 & 0.22 \\
3-Octen-2-one & 28.37 & 0.13 & 0.15 & 0.24 \\
4H-Pyran-4-one & 44.49 & 0.21 & 0.33 & 0.06 \\
1-Butanol & 20.85 & 0.70 & 0.27 & 1.42 \\
1-Pentanol & 22.57 & 0.61 & 1.07 & 1.63 \\
1-Hexanol & 26.36 & 26.16 & 22.35 & 2.10 \\
1-Heptanol & 29.69 & 1.13 & 0.98 & 2.13 \\
1-Octanol & 32.62 & 0.24 & 0.26 & 0.45 \\
1-Nonanol & 35.40 & 0.15 & 0.15 & 0.20 \\
2-Hexen-1-ol & 27.50 & 22.03 & 17.63 & 0.61 \\
1-Octen-3-ol & 29.53 & 0.15 & 0.10 & 0.29 \\
2-Hepten-1-ol & 31.35 & 0.11 & 0.21 & 0.16 \\
2,3-Butanediol & 32.29 & 11.80 & 8.66 & 18.27 \\
2-Furanmethanol & 35.73 & 0.16 & 0.15 & 0.15 \\
Benzyl alcohol & 41.20 & 2.57 & 3.81 & 0.99 \\
Acetic acid & 29.85 & 15.11 & 11.77 & 21.39 \\
Butanoic acid & 34.87 & 3.07 & 2.57 & 5.32 \\
Pentanoic acid & 37.68 & 0.20 & 0.31 & 0.38 \\
Hexanoic acid & 40.20 & 8.99 & 10.89 & 14.27 \\
Heptanoic acid & 42.63 & 0.22 & 0.28 & 0.52 \\
Octanoic acid & 44.89 & 2.47 & 14.86 & 22.96 \\
Decanoic acid & 49.15 & 0.67 & 0.41 & 1.36 \\
2-Methyl butanoic acid & 35.97 & 0.43 & 0.38 & 0.55 \\
Benzoic acid & 53.10 & 1.70 & 1.23 & 3.92 \\
Acetophenone & 35.87 & 0.09 & 0.14 & 0.11 \\
Phenol & 49.86 & 0.16 & 0.46 & 0.29 \\
\hline 1 & & & & \\
\hline
\end{tabular}

${ }^{1} \mathrm{FM}-\mathrm{BF}=$ samples with strawberry juice added prefermentation; FM$\mathrm{AF}=$ samples with strawberry juice added postfermentation.

be the main reason for the goaty flavor in fermented goat milk (Young et al., 2012; Teng et al., 2018). The highest value of octanoic acid was found in the control $(22.96 \%)$, and octanoic acid was significantly higher in FM-AF $(14.86 \%)$ than in FM-BF $(2.47 \%)$. The results indicated that strawberry juice addition prefermentation could reduce the goaty flavor of fermented goat milk more effectively than that added postfermentation.

\section{Effect of Strawberry Juice Addition \\ Pre- or Postfermentation on Microstructure of Stirred Fermented Goat Milk}

Compared with a laser particle analyzer (Mastersizer 3000), confocal laser scanning microscopy presents a more intuitive particle character. Microstructures of all stirred strawberry fermented goat milk samples in different addition technology were examined by confocal laser scanning microscopy, and the results are shown in Figure 5. Whey protein casein micelle PWP in fermented goat milk was most likely responsible for extensive structure reorganization during gel formation (Krzeminski et al., 2011). For FM-AF, the microstructure of the sample was inconspicuously changed by strawberry
FM-BF

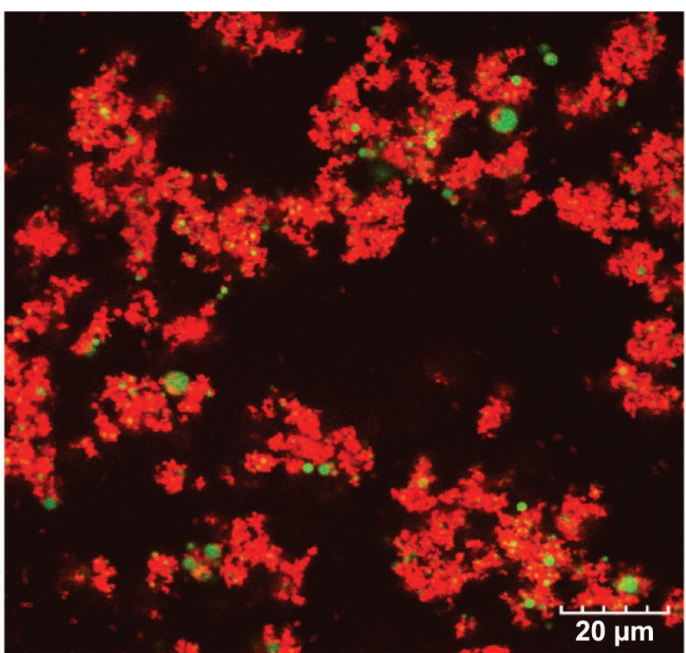

FM-AF

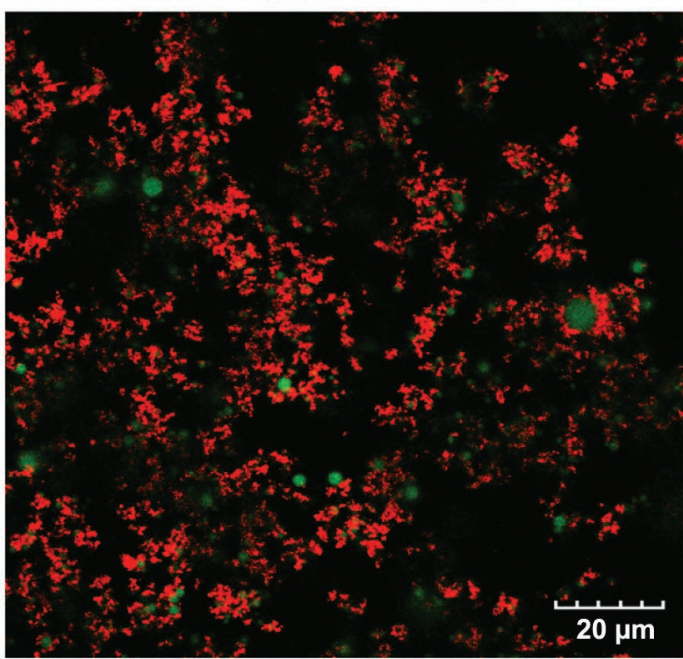

Control

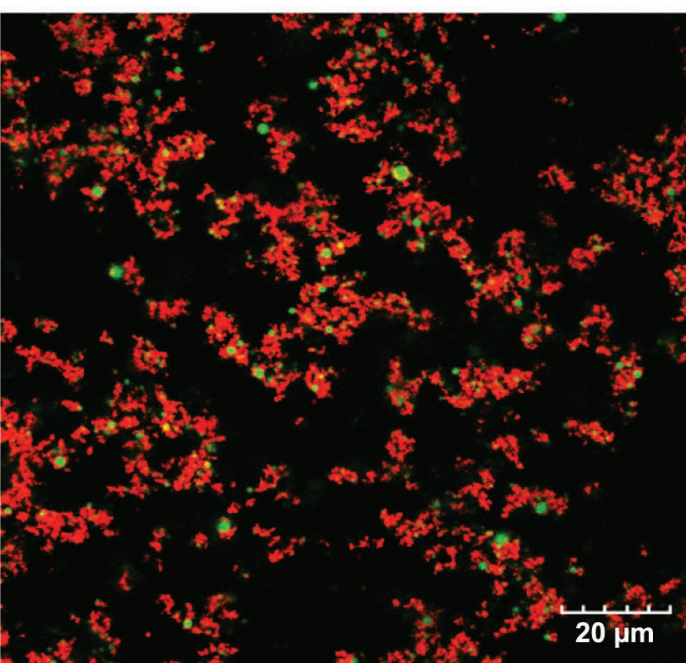

Figure 5. Microstructure of samples with strawberry juice added prefermentation (FM-BF), samples with strawberry juice added postfermentation (FM-AF), and control with protein dyed red and fat dyed green. 
juice addition, which was consistent with the result for particle size. Among all samples, FM-BF showed a gel with coarser, more porous structure but a finer protein network with smaller pores. The more compact protein network of FM-BF may be responsible for the higher physical profile, such as particle size distribution, apparent viscosity, and moduli.

\section{CONCLUSIONS}

Addition of strawberry juice to fermented goat milk prefermentation could enhance the physiochemical properties compared with samples with juice added postfermentation. Fruit and goaty flavor profiles of FM-BF were significant higher and lower, respectively, than in FM-AF in terms of the ratio of volatiles. Data indicated that strawberry juice addition prefermentation may be a good technology and that strawberry may be considered a good technique for developing flavored fermented goat milk.

\section{ACKNOWLEDGMENTS}

The authors thank The Ministry of Science and Technology of China (project no. 2013BAD18B07, Beijing, China) for the financial support of this project.

\section{REFERENCES}

Beshkova, D. M., E. D. Simova, G. I. Frengova, Z. I. Simov, and Z. P. Dimitrov. 2003. Production of volatile aroma compounds by kefir starter cultures. Int. Dairy J. 13:529-535.

Brewer, D. R., J. M. Franco, and L. A. Garciazapateiro. 2016. Rheological properties of oil-in-water emulsions prepared with oil and protein isolates from sesame (Sesamum indicum). Food Sci. Technol. 36:64-69.

Bueno, L., T. M. S. Silva, N. P. Perina, C. Bogsan, and M. N. Oliveira. 2014. Addition of strawberry, raspberry and "pitanga" pulps improves the physical properties of symbiotic yoghurts. Chem. Eng. Trans. 38:499-504.

Buldo, P., C. Benfeldt, D. M. Folkenberg, H. B. Jensen, J. M. Amigo, S. Sieuwerts, K. Thygesen, F. van den Berg, and R. Ipsen. 2016. The role of exopolysaccharide-producing cultures and whey protein ingredients in yoghurt. LWT Food Sci. Technol. 72:189-198.

Cayot, P., F. Schenker, G. Houzé, C. Sulmont-Rossé, and B. Colas. 2008. Creaminess in relation to consistency and particle size in stirred fat-free yogurt. Int. Dairy J. 18:303-311.

Cheng, H. 2010. Volatile flavor compounds in yogurt: A review. Crit. Rev. Food Sci. Nutr. 50:938-950.

Decourcelle, N., S. Lubbers, N. Vallet, P. Rondeau, and E. Guichard. 2004. Effect of thickeners and sweeteners on the release of blended aroma compounds in fat-free stirred yoghurt during shear conditions. Int. Dairy J. 14:783-789.

Dimitreli, G., E. A. Gregoriou, G. Kalantzidis, and K. D. Antoniou. 2013. Rheological properties of kefir as affected by heat treatment and whey protein addition. J. Texture Stud. 44:418-423.

do Espirito Santo, A. P., R. Perego, A. Converti, and M. N. Oliveira. 2012. Influence of milk type and addition of passion fruit peel powder on fermentation kinetics, texture profile and bacterial viability in probiotic yoghurts. LWT Food Sci. Technol. 47:393-399.
Duan, W., P. Sun, L. Chen, S. Gao, W. Shao, and J. Li. 2017. Comparative analysis of fruit volatiles and related gene expression between the wild strawberry Fragaria pentaphylla and cultivated Fragaria $\times$ ananassa. Eur. Res. Technol. 244:57-72.

Espírito-Santo, A. P., A. Lagazzo, A. L. O. P. Sousa, P. Perego, A. Converti, and M. N. Oliveira. 2013. Rheology, spontaneous whey separation, microstructure and sensorial characteristics of probiotic yoghurts enriched with passion fruit fiber. Food Res. Int. $50: 224-231$.

FAO (Food and Agriculture Organization of the United Nations). 2016. Production Data 2016. Accessed Nov. 31, 2017. http://www fao.org/faostat.html.

Gentes, M. C., S. L. Turgeon, and D. St-Gelais. 2016. Impact of starch and exopolysaccharide-producing lactic acid bacteria on the properties of set and stirred yoghurts. Int. Dairy J. 55:79-86.

Glibowski, P., and A. Kowalska. 2012. Rheological, texture and sensory properties of kefir with high performance and native inulin. J. Food Eng. 111:299-304.

Guggisberg, D., P. Piccinali, and K. Schreier. 2011. Effects of sugar substitution with Stevia, Actilight (TM) and Stevia combinations or Palatinose (TM) on rheological and sensory characteristics of low-fat and whole milk set yoghurt. Int. Dairy J. 21:636-644.

Haenlein, G. F. W. 2004. Goat milk in human nutrition. Small Rumin. Res. 51:155-163.

Huc, D., C. Michon, C. Bedoussac, and V. Bosc. 2016. Design of a multi-scale texture study of yoghurts using rheology, and tribology mimicking the eating process and microstructure characterisation. Int. Dairy J. 61:126-134.

Krzeminski, A., K. Grosshable, and J. Hinrichs. 2011. Structural properties of stirred yoghurt as influenced by whey proteins. LWT Food Sci. Technol. 44:2134-2140.

Li, N., F. Zheng, M. Liang, and B. Sun. 2010. Identification of volatile flavor compounds in Chinese Sinkiang camel-naizi using different solid phase microextraction fibers. Food Sci. Biol. 19:993-998.

Li, S., C. J. Ma, Z. M. Liu, G. Y. Gong, Z. P. Xu, A. C. Xu, and B. Z. Hua. 2014. Flavour analysis of stirred yoghurt with Cheddar cheese adding into milk. Food Sci. Technol. Res. 20:939-946.

Lucke, F. K., and P. Zangerl. 2014. Food safety challenges associated with traditional foods in German-speaking regions. Food Control 43:217-230.

Mesurolle, J., A. Saint-Eve, I. Deleris, and I. Souchon. 2013. Impact of fruit piece structure in yogurts on the dynamics of aroma release and sensory perception. Molecules 18:6035-6056.

Mokoonlall, A., S. Nobel, and J. Hinrichs. 2016a. Post-processing of fermented milk to stirred products: Reviewing the effects on gel structure. Trends Food Sci. Technol. 54:26-36.

Mokoonlall, A., J. Pfannstiel, M. Struch, R. G. Berger, and J. Hinrichs. 2016b. Structure modification of stirred fermented milk gel due to laccase-catalysed protein crosslinking in a post-processing step. Innov. Sci. Emerg. 33:563-570.

Mokoonlall, A., L. Sykora, J. Pfannstiel, S. Nobel, J. Weiss, and J. Hinrichs. 2016c. A feasibility study on the application of a laccasemediator system in stirred yoghurt at the pilot scale. Food Hydrocoll. 60:119-127.

Nguyen, P. T. M., O. Kravchuk, B. Bhandari, and S. Prakash. 2017. Effect of different hydrocolloids on texture, rheology, tribology and sensory perception of texture and mouthfeel of low-fat pot-set yoghurt. Food Hydrocoll. 72:90-104.

Nongonierma, A. B., M. Springett, J.-L. Le Quéré, P. Cayot, and A. Voilley. 2006. Flavour release at gas/matrix interfaces of stirred yoghurt models. Int. Dairy J. 16:102-110.

Pan, D. D., Z. Wu, T. Peng, X. Q. Zeng, and H. Li. 2014. Volatile organic compounds profile during milk fermentation by Lactobacillus pentosus and correlations between volatiles flavor and carbohydrate metabolism. J. Dairy Sci. 97:624-631.

Ramaswamy, H. S., and S. Basak. 1992. Pectin and raspberry concentrate effects on the rheology of stirred commercial yogurt. J. Food Sci. 57:357-360.

Schorsch, B. C., D. K. Wilkins, M. G. Jones, and I. T. Norton. 2001. Gelation of casein-whey mixtures: Effects of heating whey pro- 
teins alone or in the presence of casein micelles. J. Dairy Res. 68:471-481.

Senaka Ranadheera, C., C. A. Evans, M. C. Adams, and S. K. Baines. 2012. Probiotic viability and physico-chemical and sensory properties of plain and stirred fruit yogurts made from goat's milk. Food Chem. 135:1411-1418.

Temiz, H., Z. Tarakçı, T. Yarilgaç, and B. Dă̆. 2018. Some physicochemical properties and mineral contents of stirred yoghurts containing different fruit marmalades. Int. J. Dairy Technol. 71:264268.

Teng, F., M. G. Reis, Y. Ma, and L. Day. 2018. Effects of season and industrial processes on volatile 4-alkyl-branched chain fatty acids in sheep milk. Food Chem. 260:327-335.

Turgut, T., and S. Cakmakci. 2018. Probiotic strawberry yogurts: Microbiological, chemical and sensory properties. Probiotics Antimicrob. Proteins 10:64-70.

Varga, L., J. Sule, and P. Nagy. 2014. Short communication: Survival of the characteristic microbiota in probiotic fermented camel, cow, goat, and sheep milks during refrigerated storage. J. Dairy Sci. 97:2039-2044.

Wah, T. T., S. Walaisri, A. Assavanig, N. Niamsiri, and S. Lertsiri. 2013. Co-culturing of Pichia guilliermondii enhanced volatile flavor compound formation by Zygosaccharomyces rouxii in the model system of Thai soy sauce fermentation. Int. J. Food Microbiol. 160:282-289.

Wang, C., F. Gao, T. Zhang, Y. Wang, and M. Guo. 2015a. Physiochemical, textural, sensory properties and probiotic survivability of Chinese Laosuan Nai (protein-fortified set yoghurt) using polymerised whey protein as a co-thickening agent. Int. J. Dairy Technol. 68:261-269.

Wang, H., C. Wang, M. Wang, and M. Guo. 2017. Chemical, physiochemical, and microstructural properties, and probiotic survivability of fermented goat milk using polymerized whey protein and starter culture Kefir Mild 01. J. Food Sci. 82:2650-2658.

Wang, J., Z. Xing, W. Tang, Y. Zheng, and Y. Wang. 2015b. Isolation, identification, and potential probiotic characterization of one Lactococcus from Kefir grain. Food Sci. Biotechnol. 24:1775-1780.

Ye, M., D. Liu, R. Zhang, L. Yang, and J. Wang. 2012. Effect of hawk tea (Litsea coreana L.) on the numbers of lactic acid bacteria and flavour compounds of yoghurt. Int. Dairy J. 23:68-71.

Young, O. A., R. B. Gupta, and S. Sadooghy-Saraby. 2012. Effects of cyclodextrins on the flavor of goat milk and its yogurt. J. Food Sci. 77:S122-S127. 